\title{
Antibiotics susceptibility profile of Staphylococcus aureus isolated from selected hospital and non-hospital fomites
}

\author{
Oluwatayo Ayotunde Makinde, Ayorinde Bunmi Akinbobola*, Olubunmi Olowokanga \\ Department of Microbiology, Adekunle Ajasin University, Akungba-Akoko, Nigeria.
}

\section{ARTICLE INFO}

Article history:

Received on: 13/12/2016

Accepted on: 10/01/2017

Available online: 20/03/2017

Key words:

Staphylococcus aureus, antibiotics resistance,

fomites.

\begin{abstract}
Staphylococcus aureus is a pathogenic microorganism responsible for mild to life threatening infection. It's one of the most common cause of hospital acquired infections with community acquired $S$. aureus infection likewise widely reported. Emergence of methicillin resistant $S$. aureus represents a significant public health challenge as this limits available treatment options for $S$. aureus infections. Fomites are being increasingly recognised as a significant means of transmission of $S$. aureus infections. In this study we examined the occurrence of $S$. aureus on common hospital and non-hospital fomites and their susceptibility to commonly used antibiotics in the treatment of methicillin resistance $S$. aureus infection. Selected fomites in hospital and non-hospital environments were sampled using a cotton swab technique. Isolates were identified as $S$. aureus using their morphological characteristics on mannitol salt agar and biochemical characteristics. The susceptibility of isolated S. aureus to selected antibiotics was determined using a disc diffusion method. More than $50 \%$ of sampled fomites were positive for $S$. aureus colonisation. Hospital and non- hospital isolates of $S$. aureus generally showed a similar susceptibility pattern to selected antibiotics except in their susceptibility to vancomycin and lincomycin. Results from this study showed that fomites may present a significant risk of $S$. aureus infection.
\end{abstract}

\section{INTRODUCTION}

Staphylococcus aureus can asymptomatically inhabit the skin and mucous membrane of both human and animals. A carrier rate between $20-50 \%$ have been variously reported in healthy individuals with the nasal cavity as the most colonised body site and often acting as a reservoir for $S$. aureus infection $[1,2,3] S$. aureus is a common human pathogen responsible for various human infections ranging from mild skin infections to invasive life threatening diseases [4]. These include wound infections, bacteraemia and toxin mediated diseases such as toxic shock syndrome [5]. It's one of the most common hospital acquired pathogens and have also been variously reported as the causative agent for an increasing cases of community acquired infections $[6$, $7,8,9]$.

* Corresponding Author

Email: ayorinde.akinbobola @ aaua.edu.ng
Although the anterior nares has been variously described as the principal reservoir of $S$. aureus infections, the importance of fomites as route of transmission of $S$. aureus infection is being increasingly recognised $[10,11,12]$. With the increasing recognition of the threat pose by community acquired $S$. aureus infection to public health, investigation of $S$. aureus colonisation of community fomites is of immense public health importance. Emergence of $S$. aureus resistance to penicillin and subsequently methicillin and other commonly used antibiotics limits treatment option for staphylococcal infection, thereby posing a significant public health threat. This is more challenging in developing communities, where the use of antibiotics is less regulated, a situation that potentially encourage antibiotics resistance $[13,14]$.

In this study, we examined the occurrence of $S$. aureus on common hospital and non-hospital fomites in a community in Ondo state, south west Nigeria and the susceptibility of the isolates to antibiotics commonly used in the treatment of methicillin resistant $S$. aureus. 


\section{METHODS}

\subsection{Sample Collection}

Common fomites in a public hospital in Akoko area of Ondo state Nigeria as well as fomites in the same community were sampled using sterile swab moisten with sterile distilled water. Fomites sampled in the hospital include stethoscopes, cell phones, door knobs and drip stands while door knobs, cell phones as well as ATM machines were sampled in the community. A total of 20 sampling were each made from hospital and community fomite.

\subsection{Isolation and Identification of $S$. Aureus}

Samples were immediately transported into the laboratory and inoculated on mannitol salt agar. Inoculated plates were incubated at $37^{\circ} \mathrm{C}$ for $24 \mathrm{hrs}$. Colonies showing the characteristic ability to grow and also ferment mannitol were subjected to Gram staining, catalase and coagulase tests. Gram positive, catalase and coagulase positive cocci isolates were identified as $S$. aureus

\subsection{Antibiotics susceptibility test}

The susceptibility of $S$. aureus isolates to selected antibiotics was evaluated using disc diffusion method according to the Clinical and Laboratory Standard Institute (CLSI) 2010 guidelines [15]. All tests were performed on Mueller-Hinton agar with inoculum standardise to $0.5 \mathrm{McFarland}$ standard.

\section{RESULTS AND DISCUSSION}

More than $50 \%$ of both hospital and non-hospital fomites sampled showed $S$. aureus contamination with non-hospital fomites showing a slightly higher percentage of $S$. aureus contamination as shown in Table 1. S. aureus isolates from both hospital and non-hospital sources generally showed a similar antibiotics susceptibility profile except in their susceptibility to vancomycin and lincomycin (Table 2 ).

Table 1: Percentage of S. aureus occurrence on hospital and community fomites.

\begin{tabular}{|c|c|c|c|}
\hline Sources & 总 & 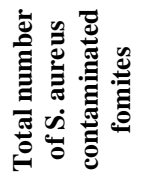 & 。 \\
\hline Hospital fomites & 20 & 11 & 55 \\
\hline Community fomites & 20 & 13 & 65 \\
\hline
\end{tabular}

S. aureus was isolated from more than $50 \%$ of the fomites sampled in this study. $S$. aureus contamination of fomites have likewise been variously reported $[16,17,18,19,20,21]$. The reported percentage of occurrence ranges between $8-60 \%$ depending on the types of sampled fomites and studied community. The relatively high percentage of $S$. aureus occurrence on both hospital and non-hospital fomites as shown in this study indicates they are potential route of $S$. aureus transmission. This represents a potential risk of staphylococcal infection for immunocompromised, diabetics and individuals with other predisposing factors such as wounds [22, 23, 24]. The ability of fomites to transmit $\mathrm{S}$. aureus infection has been demonstrated [11].

Table 2: Antibiotic sensitivity profile of Staphylococcus aureus isolated from hospital and non-hospital fomites.

\begin{tabular}{lccccc}
\hline & $\begin{array}{c}\text { Total } \\
\text { number }\end{array}$ & \multicolumn{2}{c}{$\begin{array}{c}\text { Hospital isolates } \\
\text { An=11 }\end{array}$} & \multicolumn{2}{c}{$\begin{array}{c}\text { Non-hospital isolates } \\
\text { n=13 }\end{array}$} \\
\cline { 3 - 6 } & $\begin{array}{c}\text { of } \\
\text { isolates } \\
\text { tested }\end{array}$ & $\begin{array}{c}\text { Number } \\
\text { of } \\
\text { resistant } \\
\text { isolates }\end{array}$ & $\begin{array}{c}\text { \% of } \\
\text { resistant } \\
\text { isolates }\end{array}$ & $\begin{array}{c}\text { Number } \\
\text { of } \\
\text { resistant } \\
\text { isolates }\end{array}$ & $\begin{array}{c}\text { \% of } \\
\text { resistant } \\
\text { isolates }\end{array}$ \\
\hline Cephalotin & 24 & 6 & 54.55 & 7 & 53.85 \\
Cephalexin & 24 & 7 & 63.64 & 8 & 61.54 \\
Amikacin & 24 & 8 & 72.73 & 9 & 69.23 \\
Gentamicin & 24 & 5 & 45.46 & 6 & 46.15 \\
Erythromycin & 24 & 8 & 72.73 & 11 & 84.62 \\
Chloramphenicol & 24 & 2 & 18.18 & 3 & 23.08 \\
Ciprofloxacin & 24 & 4 & 36.36 & 5 & 38.46 \\
Vancomycin & 24 & 1 & 9.09 & 0 & 0 \\
Lincomycin & 24 & 4 & 36.36 & 2 & 15.38 \\
\hline
\end{tabular}

The antibiotics susceptibility profile of isolated $S$. aureus revealed an interesting pattern. Although the antibiotics susceptibility profiles of isolates from hospital and non-hospital fomites are mostly similar, isolates from non-hospital fomites showed no or relatively lower resistance to vancomycin and lincomycin. This observation may be due to the pattern of use of these antibiotics in the studied community. Vancomycin is usually employed in the treatment of life threatening staphylococcal infections, this may be responsible for the observed low occurrence of vancomycin resistant limited only to the hospital isolates. Clarence et al. (2008) while studying the pattern of antibiotics usage in a city in Nigeria, reported no vancomycin prescription for the three years of the study period [25]. Likewise, Donkor et al. (2012) showed that vancomycin is the least selfprescribed antibiotics by a selected tertiary level student in Ghana [26].

Isolation of vancomycin resistant isolates from hospital sources has also been reported $[27,28]$. A resistance of about $10 \%$ of the isolates from hospital fomites to vancomycin represent a significant public health importance since it's usually the drug of last resort in the treatment of methicillin resistant $S$. aureus [29]. Likewise, the percentage of lincomycin resistance isolates was lower in isolates from non-hospital fomites compared to hospital associated isolates. Lincomycin resistance has been previously reported from both hospital and non-hospital sources [30]. These observations underscore the contribution of indiscriminate use of antibiotics to emergence of antibiotic resistant. More than $50 \%$ of the isolates from both hospital and non-hospital sources showed resistance to cephalotin, cephalexin, amikacin and erythromycin. This indicates wide spread resistance to these antibiotics in the studied community. 


\section{CONCLUSION}

Finding from this study revealed a wide spread contamination of both hospital and non-hospital fomites by antibiotics resistant strains of $S$. aureus in the studied community, this further show the need for the implementation of hygiene awareness and decontamination program as well as regulated use of antibiotics as a deliberate public health policy in developing communities.

\section{Financial support and sponsorship: Nil.}

Conflict of Interests: There are no conflicts of interest.

\section{REFERENCES}

1. Williams REO. Healthy carriage of Staphylococcus aureus: its prevalence and importance. Bacteriological reviews. 1963;27(1):56.

2. Wertheim HF, Melles DC, Vos MC, van Leeuwen W, van Belkum A, Verbrugh HA, Nouwen JL. The role of nasal carriage in Staphylococcus aureus infections. The Lancet infectious diseases. 2005;5(12):751-762.

3. Kluytmans J., Van Belkum A., Verbrugh H. Nasal carriage of Staphylococcus aureus: epidemiology, underlying mechanisms, and associated risks. Clinical microbiology reviews. 1997;10(3):505-520.

4. Cogen A, Nizet V, Gallo R. Skin microbiota: a source of disease or defence? British Journal of Dermatology. 2008;158(3):442-55.

5. Schlievert PM, Shands KN, Dan BB, Schmid GP, Nishimura RD. 1981. Identification and characterization of an exotoxin from Staphylococcus aureus associated with toxic-shock syndrome. Journal of Infectious Diseases. 1997;143(4):509-516.

6. Dereli N, Ozayar E, Degerli S, Sahin S, Koç F. Three-year evaluation of nosocomial infection rates of the ICU. Revista Brasileira de Anestesiologia. 2013;63(1):79-84.

7. Miliani K, Migueres B, Verjat-Trannoy D, Thiolet JM, Vaux S, Astagneau P. National point prevalence survey of healthcareassociated infections and antimicrobial use in French home care settings, May to June 2012. Euro surveillance: bulletin Europeen sur les maladies transmissibles European communicable disease bulletin. 2014;20(27).

8. Tabatabaei SM, Pour FB, Osmani S. Epidemiology of HospitalAcquired Infections and Related Anti-Microbial Resistance Patterns in a Tertiary-Care Teaching Hospital in Zahedan, Southeast Iran. International Journal of Infection. 2015;2(4).

9. Enright MC, Day NP, Davies CE, Peacock SJ, Spratt BG. Multilocus sequence typing for characterization of methicillin-resistant and methicillin-susceptible clones of Staphylococcus aureus. Journal of clinical microbiology. 2000;38(3):1008-1015.

10. Neely AN, Maley MP. Survival of enterococci and staphylococci on hospital fabrics and plastic. Journal of clinical microbiology. 2000;38(2):724-726.

11. Desai R, Pannaraj PS, Agopian J, Sugar CA, Liu GY, Miller LG. Survival and transmission of community-associated methicillinresistant Staphylococcus aureus from fomites. American journal of infection control. 2011;9(3):219-225.

12. Miller LG, Diep BA. Colonization, fomites, and virulence: rethinking the pathogenesis of community-associated methicillin-resistant Staphylococcus aureus infection. Clinical Infectious Diseases. 2008;46(5):752-760.

13. Hart C, Kariuki S. Antimicrobial resistance in developing countries. British medical journal. 1998; 317(7159):647.

14. Planta MB. The role of poverty in antimicrobial resistance. The Journal of the American Board of Family Medicine. 2007; 20(6):5339.
15. Clinical and Laboratory Standard Institute (CLSI) Performance standards for antimicrobial susceptibility testing twentieth informational supplement. M100-S20. 2010;30(1):60-73

16. Singh D, Kaur H, Gardner, WG, Treen, LB. Bacterial contamination of hospital pagers. Infection Control \& Hospital Epidemiology. 2002;23(05):274-276.

17. Smith MA, Mathewson JJ, Ulert IA, Scerpella EG, Ericsson CD. Contaminated stethoscopes revisited. Archives of internal medicine. 1996;156(1):82-84.

18. Omololu-Aso J, Kolawole DO, Omololu-Aso, OO, Ajisebutu SO. Antibiotics sensitivity pattern of staphylococcus aureus from fomites in the Obafemi Awolowo University Teaching Hospital Complex (OAUTHC) Nigeria. International Journal of Medicine and Medical Science. 2011;3(2):32-36

19. Hammuel C, Idoko MO, Migap HH, Ambrose N. Occurrence and antibiogram profile of Staphylococcus aureus isolated from some hospital environment in Zaria, Nigeria. African Journal of Microbiology Research. 2015;9(19):1304-1311.

20. Nwankwo E. Isolation of pathogenic bacteria from fomites in the operating rooms of a specialist hospital in Kano, North-western Nigeria. Pan African Medical Journal. 2013;12(1).

21. Otter JA, French GL. Bacterial contamination on touch surfaces in the public transport system and in public areas of a hospital in London. Letters in applied microbiology. 2009;49(6):803-805.

22. McKinnell JA, Miller LG, Eells SJ, Cui E, Huang SS. A systematic literature review and meta-analysis of factors associated with methicillin-resistant Staphylococcus aureus colonization at time of hospital or intensive care unit admission. Infection Control \& Hospital Epidemiology. 2013;34(10):1077-86.

23. Del Rio A, Cervera C, Moreno A, Moreillon P, Miró JM. Patients at risk of complications of Staphylococcus aureus bloodstream infection. Clinical Infectious Diseases. 2009;48(Supplement 4):S246S53.

24. Early GJ, Seifried SE. Risk factors for community-associated Staphylococcus aureus skin infection in children of Maui. Hawaii Journal of Medicine \& Public Health. 2012;71(8).

25. Clarence YS, Edrin YO, Odeh EN. Pattern of antibiotic usage by adult populations in the city of Benin, Nigeria. Scientific Research and Essays. 2008;3(3):081-5.

26. Donkor ES, Tetteh-Quarcoo PB, Nartey P, Agyeman IO. Selfmedication practices with antibiotics among tertiary level students in Accra, Ghana: a cross-sectional study. International journal of environmental research and public health. 2012;9(10):3519-29.

27. Thati V, Shivannavar CT, Gaddad SM. Vancomycin resistance among methicillin resistant Staphylococcus aureus isolates from intensive care units of tertiary care hospitals in Hyderabad. The Indian journal of medical research. 2011;134(5):704.

28. Oliveira GA, Dell'Aquila AM, Masiero RL, Levy CE, Gomes MS, Cui L, et al. Isolation in Brazil of nosocomial Staphylococcus aureus with reduced susceptibility to vancomycin. Infection Control \& Hospital Epidemiology. 2001;22(07):443-8.

29. Gardete S, Tomasz A. Mechanisms of vancomycin resistance in Staphylococcus aureus. The Journal of clinical investigation. 2014;124(7):2836-40

30. Anwar M, Bokhari S. Antimicrobial resistance of community and hospital acquired Staphylococcus aureus isolates to oxacillin and glycopeptides. Journal of the College of Physicians and Surgeons-Pakistan: JCPSP. 2003; 13(1):33-6.

\section{How to cite this article:}

Makinde OA, Akinbobola A, Olowokanga O. Antibiotics susceptibility profile of Staphylococcus aureus isolated from selected hospital and non-hospital fomites. J App Biol Biotech. 2017; 5 (02): 094-096. DOI: 10.7324/JABB.2017.50215 